\title{
Can the addition of carbon nanoparticles to a polyimide
} membrane reduce plasticization?

\author{
Shinji Kanehashi ${ }^{1,2}$, George Q. Chen ${ }^{1}$, \\ David Danaci ${ }^{1}$, Paul A.Webley ${ }^{1}$, and Sandra E. Kentish ${ }^{1 *}$
}

${ }^{1}$ Peter Cook Centre for Carbon Capture and Storage, Department of Chemical and Biomolecular Engineering, The University of Melbourne, Victoria 3010, Australia.

2 Department of Organic and Polymer Materials Chemistry, Tokyo University of Agriculture and Technology, 2-24-16 Nakacho, Koganei, Tokyo 184-8588, Japan

* Correspondence to Sandra E. Kentish

Tel : +61-3-8344-6682, Fax : +61-8344-4153

E-mail : sandraek@unimelb.edu.au 


\begin{abstract}
Mixed matrix membranes (MMMs) for carbon dioxide $\left(\mathrm{CO}_{2}\right)$ separation composed of a commercial aromatic polyimide as a host matrix and carbon nanoparticles as a filler phase have been prepared by a casting method. The solubility of $\mathrm{CO}_{2}$ in the $\mathrm{MMM}$ could be predicted within error from the pure component isotherms, suggesting that the sorption of polymer to the nanoparticles did not significantly reduce the availability of sites for $\mathrm{CO}_{2}$ to adsorb. The $\mathrm{CO}_{2}$ permeability increased with filler loading without a reduction in the gas selectivity, reflecting the increase in fractional free volume provided by the carbon nanoparticles. This was reflected in significant changes in the $\mathrm{CO}_{2}$ diffusivity. However, contrary to prior work, the use of the carbon nanoparticles was unable to reduce the effects of plasticisation by either $\mathrm{CO}_{2}$ or water. Changes in the permeability of both water vapor and carbon dioxide occurred with time, particularly for relative humidities beyond $60 \%$. The lack of plasticization resistance may reflect the use of sub-micron nanoparticles rather than larger ones.
\end{abstract}

Keywords: Mixed matrix membrane; Carbon dioxide; Polyimide; Carbon; Plasticization 


\section{INTRODUCTION}

Membrane technology is an attractive approach to gas and vapour separation due to its ease of operation, energy efficiency and cost-effectiveness, relative to other techniques such as solvent absorption, adsorption, and cryogenic distillation.[1] Polymer membrane-based separation technologies have been applied in industrial applications including natural gas sweetening, hydrogen recovery and oxygen enrichment. They are also seen to have potential for post combustion capture of carbon dioxide. However, there is a well-known trade-off in dense polymer membranes between gas permeability and selectivity for any given pair of components.[2] One of the effective ways to overcome this trend is to use mixed matrix membranes (MMMs) which combine the benefits of both polymer substrates and organic and/or inorganic fillers.[3, 4] To date, a large variety of mixed matrix membranes using carbon nanotubes, carbon molecular sieves,[5, 6] activated carbon,[7-9] zeolites,[10] silica,[11-13] and metal organic frameworks (MOFs)[14-16] have been investigated for gas separation applications. These systems are attractive because of their enhanced thermal, chemical, and mechanical stability in addition to their improved gas permeation, when compared to homogeneous polymer membranes.

Some workers have shown that the addition of fillers such as metal organic frame works (MOFs)[17], mesoporous silica [18] and zeolites[19] can suppress high pressure $\mathrm{CO}_{2^{-}}$ induced plasticization. This is a phenomenon often observed in glassy polymers where the polymer matrix expands rapidly beyond a critical penetrant pressure, referred to as the plasticization pressure. It is claimed that the fillers used in mixed matrix systems enhance the interaction between polymer and fillers and thus act as pseudo-crosslinkers. However, other workers find the addition of ZIF-8 nanoparticles ineffective in reducing $\mathrm{CO}_{2}$ plasticisation, unless a cross-linkable moiety is specifically added.[20] 
Carbon membranes have also been widely investigated as homogeneous systems derived from polymer precursors.[21-23] For example, we have previously reported the performance of microporous (diameter, $d<2 \mathrm{~nm}$ ) carbon membranes for carbon dioxide $\left(\mathrm{CO}_{2}\right)$ capture.[24] Gas adsorption and molecular simulation experiments suggested that $\mathrm{CO}_{2}$ is more readily adsorbed on microporous carbon than methane $\left(\mathrm{CH}_{4}\right)$ and nitrogen $\left(\mathrm{N}_{2}\right)$. [25] Further, it has been shown that the selectivity of carbon membranes for more strongly adsorbed molecules such as $\mathrm{CO}_{2}$ can be enhanced beyond that in a polymeric system by surface diffusion.[26] Indeed, in some cases, more of the diffusing species can migrate in the surface layer than through the pore volume.[27] Importantly, we have also shown that carbon membranes are resistant to the impact of a range of gas impurities, including water, which is the most common contaminant in post-combustion capture.[28]

In our more recent work, we have also shown that carbon nanoparticles can be similarly effective in improving the gas separation performance in mixed matrix systems.[29, 30] Further, these particles are likely to be available at more moderate cost than additives such as metal organic frameworks (MOFs). In this work, we expand on these results to provide a more detailed analysis of the effectiveness of carbon-based mixed matrix systems across a range of operating pressures and water vapor humidities. A specific focus of the manuscript is to determine whether the addition of these nanoparticles can reduce plasticization of the membrane by both water vapor and $\mathrm{CO}_{2}$, thus providing a material that provides for more stable operation in the field, with no loss in separation performance. 


\section{EXPERIMENTAL}

\subsection{Materials}

The base polymer material used as host matrix in this research is Matrimid ${ }^{\circledR} 5218(3,3,4,4-$ benzophenone tetracarboxylicdianhydride-diaminophenylidane) polyimide purchased from Huntsman Advanced Materials Americas Inc, America, in a powder state. This polyimide was purified by dissolution in dichloromethane (DCM, Analytical reagent, Chem-Supply, Australia) and re-precipitation using methanol (Analytical reagent, Chem-Supply, Australia) to remove impurities. Carbon nanoparticles were purchased from Sigma-Aldrich Inc., America. The physical properties of the carbon nanoparticles are summarized in Table 1. Both the polyimide and carbon nanoparticles were dried at $100^{\circ} \mathrm{C}$ overnight under vacuum to remove moisture before use.

Pure gases $\left(\mathrm{O}_{2}, \mathrm{~N}_{2}, \mathrm{CO}_{2}\right.$, and $\left.\mathrm{CH}_{4}\right)$ and gas mixtures $\left(10 \% \mathrm{CO}_{2}\right.$ in $\mathrm{CH}_{4}$ and $10 \% \mathrm{CO}_{2}$ in $\mathrm{N}_{2}$ ) were purchased from Coregas Australia with at least 99.5\% purity.

\subsection{Mixed matrix membrane preparation}

Separate solutions of dichloromethane containing 3-4 wt $\%$ of nanoparticles and $3-4 \mathrm{wt} \%$ of polymer were prepared. These separate solutions were stirred overnight at room temperature and then sonicated (Unisonics, Australia) for 30 minutes within an ice bath. The two solutions were mixed together in different proportions and then again treated by physical stirring overnight and ultrasonication for 30 minutes.

Base Matrimid ${ }^{\circledR}$ membranes and mixed matrix membranes of different filler loadings $(10,20$, and $30 \mathrm{wt} \%$ nanoparticles) were prepared from such solutions by a standard casting method.[31] A homogeneous polymer/filler solution was cast onto a glass petri dish which was covered to prevent contamination and left at room temperature for 24-48 hours. The homogeneous membranes were then removed from the petri dish using a small amount of 
distilled water. The membrane was placed in a vacuum oven at $35^{\circ} \mathrm{C}$ for 24 hours and further dried at $100^{\circ} \mathrm{C}$ for 24 hours. The thickness of the well-dried membrane varied from 60 to 80 $\mu \mathrm{m}$, as measured by a micrometer (MDC-25MX, Mitsutoyo, Japan), giving an accuracy of \pm $1 \mu \mathrm{m}$.

The volume fraction of carbon particle $\left(\phi_{\text {filler }}\right)$ in the membrane was calculated using the following equation:

$$
\phi_{\text {filler }}=\frac{w_{\text {filler }}}{w_{\text {filler }}+\frac{\rho_{\text {filler }}}{\rho_{\text {polymer }}}\left(1-w_{\text {filler }}\right)}
$$

where $w_{\text {filler }}$ is the weight fraction of carbon particle added to the membrane. $\rho_{\text {polymer }}$ and $\rho_{\text {filler }}$ are the density of polymer and carbon particle, respectively.

\subsection{Characterization}

The membrane density $(\rho)$ was determined based on the Archimedean principle at room temperature $\left(24 \pm 1{ }^{\circ} \mathrm{C}\right)$.[32] Dense membranes were weighed using an analytical balance (Mettler Toledo AB204-5) in air $\left(w_{\text {air }}\right)$ and then in ethanol (Undenatured AR 100\%, Chem-Supply, Australia) $\left(w_{E t O H}\right)$. This experiment was performed repeatedly using several different membranes to ensure reproducibility. As a comparison, the theoretical density ( $\rho_{\text {theory }}$ ) of the MMMs was calculated using the following equation:

$$
\rho_{\text {theory }}=\frac{1}{\frac{1-w_{\text {filler }}}{\rho_{\text {polymer }}}+\frac{w_{\text {filler }}}{\rho_{\text {filler }}}}
$$

The difference between the theoretical and the experimental density $\left(\rho_{\text {exp }}\right)$, provides an indication of the additional voids created between the nanoparticles and the surrounding polymer[33] This void volume fraction, or additional free volume, $\phi_{\mathrm{V} \text { oid }}$ can be estimated from: 


$$
\phi_{\text {Void }}=1-\left(\frac{\rho_{\exp }}{\rho_{\text {theory }}}\right)
$$

The FFV of dense polymeric membranes can be characterized by the following equation;

$$
F F V=\frac{V-1.3 V_{W}}{V}
$$

where $V$ is the specific volume of polymer, and $V_{w}$ is the van der Waals volume [34-36]. The $F F V$ value calculated for pure Matrimid using this approach was 0.167 . The $F F V$ of the carbon was determined in our previous work from the pore volume and the particle density as $0.540[29$, 30]. The $F F V$ of the ideal MMM is then expressed as Equation (5):

$$
F F V=F F V_{\text {polymer }}\left(\phi_{\text {polymer }}\right)+F F V_{\text {filler }}\left(\phi_{\text {filler }}\right)
$$

When the MMM includes a significant void volume fraction, the total $F F V$ becomes that shown in Equation 6:

$$
F F V=F F V_{\text {polymer }}\left(\phi_{\text {polymer }}\right)+F F V_{\text {filler }}\left(\phi_{\text {filler }}\right)+\phi_{\text {voids }}
$$

A differential scanning calorimeter (DSC8500, Perkin Elmer, Shelton USA) was used to measure polymer glass transition temperature, $T_{\mathrm{g}}$. Samples were heated over the temperature range of $50-400^{\circ} \mathrm{C}$ at a rate of $10^{\circ} \mathrm{C} / \mathrm{min}$ under nitrogen. $T_{\mathrm{g}}$ was determined as the midpoint of the slope change in the second heating scan.

Wide-angle X-ray diffraction (WAXD) measurements were performed on a D8 advance (Bruker, Germany) at 5 seconds per step of $0.02^{\circ}$ using a Ni-filtered $\mathrm{CuK} \alpha$ radiation source at $40 \mathrm{kV}$ and $30 \mathrm{~mA}$. The dispersion angle was between 5 and $50^{\circ}$. The $d$-spacing, which represents the mean distance between polymer chains, was calculated using Bragg's Law (Equation 7);

$$
\lambda=2 d \sin \theta
$$

where $\lambda$ is the wavelength of the radiation, $1.54 \AA$, and $2 \theta$ is the maximum intensity in a halo peak. 


\subsection{Pure and mixed gas permeation}

The pure gas permeability of $\mathrm{O}_{2}, \mathrm{~N}_{2}, \mathrm{CO}_{2}$, and $\mathrm{CH}_{4}$ were determined by the constantvolume/variable-pressure (CVVP) method, which measures the steady-state gas flux through a membrane of known thickness under a given pressure difference.[37] The gas permeation measurement is performed with a leak rate of below $1.0 \times 10^{-6}$ torr/s, which is negligible in the case of well dried defect free samples. Pure gas permeation data were determined at $35^{\circ} \mathrm{C}$ and $2 \mathrm{~atm}$ feed gas pressure using a minimum of two membrane samples to ensure the reproducibility of the experimental results. The gas permeation coefficient $P$ (barrer $=\times 10^{-10}$ $\left.\mathrm{cm}^{3}(\mathrm{STP}) \mathrm{cm} /\left(\mathrm{cm}^{2} \cdot \mathrm{s} \cdot \mathrm{cmHg}\right)\right)$ was determined from the slope of the time-pressure curve at steady state.

Gas permeability in both pure $\mathrm{CO}_{2}$ and $\mathrm{CH}_{4}$ and in mixtures of $10 \% \mathrm{CO}_{2}$ in $\mathrm{CH}_{4}$ was also determined at $35^{\circ} \mathrm{C}$ for a sequence of pressures from 2 to $10 \mathrm{~atm}$ using a constant-pressure/ variable-volume (CPVV) apparatus designed and built in-house.[38, 39]. In addition, the permeability in humid gas mixtures of $10 \% \mathrm{CO}_{2}$ in $\mathrm{CH}_{4}$ and $10 \% \mathrm{CO}_{2}$ in $\mathrm{N}_{2}$ were recorded using this approach across a range of humidities at a total feed gas pressure of $7.5 \mathrm{~atm}$. The gas permeability was recorded one hour after stabilization at each pressure. For these CPVV experiments, the flux of each gas component $\left(J_{i}\right)$ passing through the membrane was evaluated by:

$$
J_{i}=\frac{Q \cdot x_{i}}{A}
$$

where $Q$ is the total permeate flowrate $\left(\mathrm{cm}^{3}(\mathrm{STP}) \mathrm{s}^{-1}\right), x_{i}$ is the mol fraction of the gas in the permeate stream and $A$ is the effective membrane area $\left(\mathrm{cm}^{2}\right)$. The permeate mol fractions were determined by gas chromatography (CP-3800, Varian, Inc., Australia). The permeability of each gas component was then determined from Equation 9:

$$
P_{i}=\frac{J_{i} \cdot \ell}{\left(p_{i, \text { feed }}-p_{i, \text { permeate }}\right)}
$$


where $p_{i, f e e d}$ and $p_{i, p e r m e a t e}$ the partial pressure $(\mathrm{kPa})$ of component $i$ on the feed and permeate side of the membrane respectively and $\ell$ is the membrane thickness.

The ideal gas selectivity $(\alpha(\mathrm{A} / \mathrm{B}))$ of gas A over gas B was expressed as the ratio of their permeability coefficients $\left(P_{A}\right.$ and $\left.P_{B}\right)$ (Equation 10).

$$
\alpha(A / B)=\frac{P_{A}}{P_{B}}
$$

\section{5. $\mathrm{CO}_{2}$ sorption}

$\mathrm{CO}_{2}$ sorption measurements were conducted on a Rubotherm magnetic suspension balance (Rubotherm $\mathrm{GmbH}$, Germany) at $35^{\circ} \mathrm{C}$ and up to $40 \mathrm{~atm}$. The sample was loaded into the chamber and evacuated at $35^{\circ} \mathrm{C}$ for at least 12 hours prior to each experiment. The chamber was dosed with gas to the desired pressure and equilibrated at each pressure for 30 minutes. Thermal equilibrium due to adiabatic compression of the gas was generally achieved within 10 minutes. The volume of the system was determined via helium measurement to correct for any changes in buoyancy due to the change in gas pressure. The $\mathrm{CO}_{2}$ sorption isotherm was characterized using the dual-mode sorption model according to Equation 11:[36]

$$
C=C_{D}+C_{H}=k_{D} p+\frac{C_{H}^{\prime} b p}{1+b p}
$$

where $C_{H}$ is the gas concentration in the Langmuir-type hole filling sites and $C_{D}$ is the concentration in the equilibrium or Henry's Law regions. The sorption coefficient in these equilibrium regions is $k_{D}\left(\mathrm{~cm}^{3}(\mathrm{STP}) /\left(\mathrm{cm}^{3}\right.\right.$ (polymer atm), $b$ is the Langmuir affinity parameter (1/atm), and $C^{\prime}{ }_{H}$ is the Langmuir capacity parameter $\left(\mathrm{cm}^{3}(\mathrm{STP}) /\left(\mathrm{cm}^{3}\right.\right.$ (polymer)). For the carbon nanoparticles, the Henry's Law concentration was set to zero. 


\section{RESULTS AND DISCUSSION}

\subsection{Characterization}

The membrane density of the base Matrimid is measured as $1.223 \pm 0.019 \mathrm{~g} / \mathrm{cm}^{3}$, which is in good agreement with the literature.[40] The density of the carbon nanoparticle is given by the manufacturer as $1.887 \mathrm{~g} / \mathrm{cm}^{3}$. Figure 1 presents the effect of filler loading on the membrane density of MMMs formed from the mixing of these two materials. The difference between the experimental and theoretical densities can be characterized by defining a void volume fraction $\left(\bigotimes_{\text {oids }}\right.$ ) as expressed in Equation (3) [33].

As presented in Figure 1(a), the difference between experimental and theoretical densities increased with the filler loading suggesting either a slight error in the reported density of the filler, or the development of a small amount of free space between the carbon nanoparticles and the polymer phases $(0-2 \mathrm{vol} \%$ of the total membrane sample).[29] This generation of additional free volume is well known to occur in mixed matrix systems.[33, 41]. The effect of this additional free volume upon the total free volume is shown in Figure 1(b), using Equations 5 and 6.

Figure 2 presents the relationship between the glass transition temperature and filler loading. The $T_{\mathrm{g}}$ of the base Matrimid was $310^{\circ} \mathrm{C}$ which is consistent with the literature values.[42] The $T_{\mathrm{g}}$ of $\mathrm{MMMs}$ increases from $315^{\circ} \mathrm{C}$ to $319^{\circ} \mathrm{C}$ with increasing filler loading, indicating that the membrane becomes more rigid as the carbon particles are incorporated. This is consistent with visual observations of the membranes becoming less flexible and more brittle as the loading increased. Similar results of this increase in $T_{\mathrm{g}}$ of MMMs has been reported for Matrimid-based MMMs with carbon molecular sieves (CMS) and MOFs.[5, 43]

Figure 3 presents the WAXD profile of the composite membranes and carbon. All profiles showed broad peaks indicating that these are not crystalline structures but in an amorphous state. The $d$-spacing of Matrimid was $5.7 \AA\left(2 \theta=15.4^{\circ}\right)$ which is in good 
agreement with the literature.[44] This peak persists in the mixed matrix systems, suggesting that the carbon nanoparticles, while increasing polymer rigidity, did not significantly affect the distance between polymer segments. Peaks for the carbon were observed at $25^{\circ}(d$-spacing $=$ $3.6 \AA)$ and $43^{\circ}(d$-spacing $=2.1 \AA)$. Interestingly, the peak at $25^{\circ}$ appears to shift to a smaller pore size $\left(30^{\circ}, d\right.$-spacing $\left.=3.0 \AA\right)$ in the mixed matrix membranes. This change in peak position may relate to the penetration of polymer chains into these pores[45], or it may simply reflect variability within the carbon nanoparticles themselves. However, it should be noted that the WAXD analysis covers only a very limited range of void sizes. The manufacturer indicates that the average pore size of the carbon is $64 \AA$, which is well outside the range considered here.

\subsection{Pure and mixed gas permeation and separation}

Figure 4 presents the effect of filler loading on the single dry gas permeability and selectivity of the mixed matrix membranes at 2 atm and $35^{\circ} \mathrm{C}$, which is a typical condition of postcombustion capture. The values for pure Matrimid are in good agreement with literature values.[46] All gas permeabilities increase with the loading of carbon and in the order $\mathrm{CO}_{2}$ (kinetic diameter: $3.30 \AA)>\mathrm{O}_{2}(3.46 \AA)>\mathrm{N}_{2}(3.64 \AA)>\mathrm{CH}_{4}(3.80 \AA)$, regardless of the carbon loading.[47] This order reflects the kinetic diameter of each penetrant as expected for a diffusivity selective glassy polymer [48]. Conversely, there is little, if any, change in the gas selectivities for any gas pair. This type of behavior has been reported previously for mixed matrix systems $[14,49,50]$ and in our own earlier reports $[29,30]$ and reflects the increasing $F F V$ in the membranes provided by the nanoparticles (Figure 1).

Figure 5 presents the pressure dependence of the pure and mixed $\mathrm{CO}_{2}$ and $\mathrm{CH}_{4}$ permeability of the mixed matrix membranes. The dry pure gas permeabilities decrease with increasing total feed pressure. This is typical behavior of glassy polymer membranes owing 
to the decrease in solubility.[51] However, when the feed pressure reaches $10 \mathrm{~atm}$, the pure $\mathrm{CO}_{2}$ permeability increases, indicating $\mathrm{CO}_{2}$-induced plasticization. This plasticization pressure is consistent with other workers for Matrimid.[51, 52] Furthermore, the $\mathrm{CO}_{2}$ permeability becomes time dependent at this pressure. Importantly, the addition of the carbon nanoparticles was unable to prevent the onset of plasticization at the plasticization pressure, or to reduce the rate of plasticization in the following ten hours (see Figure 6). This is in contrast to other workers who have shown that the addition of nanoparticles to a polymer acts to prevent plasticization. [17-19]

The $\mathrm{CO}_{2}$ permeability under dry mixed gas conditions is identical within the error margins to the pure gas data below $10 \mathrm{~atm}$ total feed pressure. This reflects the fact that while the lower $\mathrm{CO}_{2}$ partial pressure should lead to a higher pure gas solubility, the presence of the methane provides competition for these Langmuir sorption sites[53]. However, no plasticization is observed at $10 \mathrm{~atm}$ feed pressure. The $\mathrm{CO}_{2}$ permeability continues to decrease because the partial pressure of $\mathrm{CO}_{2}(1 \mathrm{~atm})$ is much lower than that of pure $\mathrm{CO}_{2}$ at $10 \mathrm{~atm}$.

\section{3. $\mathrm{CO}_{2}$ sorption}

Figure 7 presents the sorption isotherms of the base Matrimid, the carbon nanoparticles, and the $20 \mathrm{wt} \%$ mixed matrix membrane. The $\mathrm{CO}_{2}$ sorption isotherms in Matrimid and the $20 \mathrm{wt} \%$ membranes were concave to the pressure axis, indicating typical dual-mode sorption behavior. The $\mathrm{CO}_{2}$ uptake of carbon is greater than that of Matrimid, suggesting that the $\mathrm{CO}_{2}$ uptake of the mixed matrix membranes will increase with filler loading as is observed for the $20 \mathrm{wt} \%$ membrane. The dual-mode sorption parameters of Matrimid, determined from Equation 5 are slightly different to those in the literature.[40, 54, 55] (see Table 2). This reflects differences in the casting solvent and annealing conditions.[51] A simple Langmuir sorption isotherm can be used to model the carbon nanoparticle. The $C^{\prime}{ }_{\mathrm{H}}$ of the carbon particle is significantly 
larger than that of Matrimid, but similar to that observed for other activated carbons (Table 2). [56]

If an additive model is assumed, the $\mathrm{CO}_{2}$ concentration in the mixed matrix membranes can be expressed simply as:

$$
C=\phi_{\text {filler }} C_{\text {filler }}+\left(1-\phi_{\text {filler }}\right) C_{\text {polymer }}
$$

where $C_{\text {filler }}$ and $C_{\text {polymer }}$ are the concentrations of $\mathrm{CO}_{2}$ in the filler and polymer, respectively. This equation provides a good fit to the MMM curve within experimental error, as presented in Figure 7. This indicates that the available sites for $\mathrm{CO}_{2}$ sorption to the nanoparticles are not reduced significantly from polymer adsorbing to their surface.

The average diffusion coefficient, $D_{\text {ave }}$ can be estimated from the concentrations at the feed (1) and permeate (2) faces of the membrane:

$$
P=\frac{D_{\text {ave }}\left(C_{1}-C_{2}\right)}{p_{1}-p_{2}}
$$

By setting $C_{2}=p_{2}=0$, the average diffusion coefficient can be determined from the solubility based on the upstream conditions $\left(S_{1}=C_{1} / p_{1}\right)$. Figure 8 presents the resulting $\mathrm{CO}_{2}$ diffusion coefficients of the base Matrimid and $20 \mathrm{wt} \%$ mixed matrix membrane as a function of feed pressure at $35^{\circ} \mathrm{C}$. The diffusion coefficients of all membranes increased with increasing feed pressure. This suggests that membrane swelling is in fact occurring to some extent at all feed pressures, rather than just above the plasticization pressure, where polymer relaxation becomes dominant. The infinite dilution diffusion coefficient, $D_{0}$ is obtained from the extrapolation of these lines gives $5.45 \times 10^{-9} \mathrm{~cm}^{2} / \mathrm{s}$ for Matrimid, which is within the range of values predicted by other authors [57-59]. The diffusivity increases to $8.90 \times 10^{-9} \mathrm{~cm}^{2} / \mathrm{s}$ for the $20 \mathrm{wt} \% \mathrm{MMM}$, respectively, reflecting the increased fractional free volume from the incorporation of carbon particles. However, there is again no evidence of any reduction in membrane swelling from the addition of nanoparticles. 
Figure 9 presents the water vapor permeability through Matrimid and the $20 \mathrm{wt} \%$ $\mathrm{MMM}$ as a function of water activity in a $\mathrm{CH}_{4} / \mathrm{CO}_{2}$ mixture at $35^{\circ} \mathrm{C}$ and 7.5 bar. The water permeability of both membranes slightly increases at water activity of 0.2-0.6 due to increasing water sorption. Beyond these activities it the permeability increases more rapidly due to the plasticization by water.[39] The water vapor permeability of the MMM is slightly higher than that of Matrimid across all water activities. Importantly, the nanoparticles are again unable to restrict the effects of plasticization.

Figure 10 presents the changes in the permeability of $\mathrm{CO}_{2}$ and $\mathrm{N}_{2}$ through a $20 \mathrm{wt} \%$ MMM as a function of time in $\mathrm{N}_{2} / \mathrm{CO}_{2}$ mixture at $35^{\circ} \mathrm{C}, 7.5$ bar and a water activity $\alpha>0.9$. As shown in our prior work, the permeability and selectivity under dry conditions is higher than under humid conditions due to competitive sorption. However, once the membranes are exposed to humid conditions, the permeability increases gradually and the selectivity decreases with time, again reflective of plasticization due to the presence of water vapor. The $\mathrm{CO}_{2}$ permeability after 7 days was $14 \%$ greater, while the selectivity of $\mathrm{CO}_{2} / \mathrm{N}_{2}$ were $12 \%$ lower than that of the initial performance (0 days). This again shows that the carbon nanoparticles are ineffective in limiting plasticization effects.

A possible reason for the lack of plasticization resistance could be a weak interaction between the polymer and the carbon nanoparticles that does not facilitate a pseudo-crosslinking role. Alternatively, it may reflect the impact of nanoparticle size. The particles here are typically $0.18 \mu \mathrm{m}$ in size [29]. Askari et al.[20] also used sub-micron particle sizes (0.02 $0.08 \mu \mathrm{m})$ and did not observe any reduction in plasticization unless the nanoparticles where chemically crosslinked to the polymer. Conversely, workers who do see a reduction in plasticization use particles of micron or greater size (Shahid et al. uses $<5 \mu \mathrm{m}$ [17], Adams et al. uses 0.5 to $1.5 \mu \mathrm{m}$ [19] and Khan et al. uses $1-2 \mu \mathrm{m}$ [18]). These larger particle sizes will alter the way that the polymer can increase in free volume during the plasticization process. 


\section{CONCLUSION}

We have prepared dense polyimide-carbon MMMs containing up to $30 \mathrm{wt} \%$ loading by a casting method. The experimental densities of the MMMs were only slightly lower than those theoretically predicted, suggesting that interfacial gaps between the polyimide and particles were small. The $\mathrm{CO}_{2}$ solubility for the MMM system was readily predicted from the sorption isotherms of the individual components, indicating that the availability of sorption sites was not reduced by their interactions. The $\mathrm{CO}_{2}$ permeability increased with carbon loading without a reduction in the gas selectivity, reflecting the increase in fractional free volume provided by the carbon nanoparticles. The $\mathrm{CO}_{2}$ diffusivity also increased in line with the increase in fractional free volume afforded by the nanoparticles. The presence of water vapor in the feed gas stream reduced the membrane performance due to competitive sorption and caused membrane plasticization. Contrary to work presented by other researchers, the addition of carbon nanoparticles was unable to reduce the effects of plasticization by either $\mathrm{CO}_{2}$ or water vapor. We speculate that this reflects the small, sub-micron particle sizes used here, relative to the larger particles used by other workers.

\section{ACKNOWLEDGEMENTS}

This research was supported by the Scientific and Industry Endowment Fund in Australia (SIEF Grant ID RP02-035) and the Sasakawa Scientific Research Grant from The Japan Science Society (28-228). Specialist gas infrastructure was funded by the Australian Research Council (LE120100141) and by the Australian Government Education Investment fund and this support is also gratefully acknowledged 


\section{REFERENCES}

[1] R.W. Baker, Membrane Technology and Applications, McGraw-Hill, New York, 2000.

[2] L.M. Robeson, The upper bound revisited, J. Membr. Sci., 320 (2008) 390-400.

[3] G. Dong, H. Li, V. Chen, Challenges and opportunities for mixed-matrix membranes for gas separation, J. Mat. Chem. A, 1 (2013) 4610-4630.

[4] M. Rezakazemi, A. Ebadi Amooghin, M.M. Montazer-Rahmati, A.F. Ismail, T. Matsuura, State-of-the-art membrane based CO2 separation using mixed matrix membranes (MMMs): An overview on current status and future directions, Prog. Polym. Sci., 39 (2014) 817-861.

[5] D.Q. Vu, W.J. Koros, S.J. Miller, Mixed matrix membranes using carbon molecular sieves: I. Preparation and experimental results, J. Membr. Sci., 211 (2003) 311-334.

[6] A. Singh, W.J. Koros, Significance of entropic selectivity for advanced gas separation membranes, Ind. Eng. Chem. Res., 35 (1996) 1231-1234.

[7] M. Anson, J. Marchese, E. Garis, N. Ochoa, C. Pagliero, ABS copolymer-activated carbon mixed matrix membranes for CO2/CH4 separation, J. Membr. Sci., 243 (2004) 19-28.

[8] J. Marchese, M. Anson, N.A. Ochoa, P. Prádanos, L. Palacio, A. Hernández, Morphology and structure of ABS membranes filled with two different activated carbons, Chem. Eng. Sci., 61 (2006) 5448-5454.

[9] M.G. García, J. Marchese, N.A. Ochoa, High activated carbon loading mixed matrix membranes for gas separations, J Mater Sci, 47 (2012) 3064-3075.

[10] M. Rostamizadeh, M. Rezakazemi, K. Shahidi, T. Mohammadi, Gas permeation through H2-selective mixed matrix membranes: Experimental and neural network modeling, Int. J. Hydrogen Energy, 38 (2013) 1128-1135.

[11] Z. He, I. Pinnau, A. Morisato, Nanostructured poly(4-methyl-2-pentyne)/silica hybrid membranes for gas separation, Desalination, 146 (2002) 11-15.

[12] T.C. Merkel, Z. He, I. Pinnau, B.D. Freeman, P. Meakin, A.J. Hill, Effect of nanoparticles on gas sorption and transport in poly(1-trimethylsilyl-1-propyne), Macromolecules, 36 (2003) 6844-6855.

[13] T.C. Merkel, B.D. Freeman, R.J. Spontak, Z. He, I. Pinnau, P. Meakin, A.J. Hill, Sorption, transport, and structural evidence for enhanced free volume in poly(4-methyl-2-pentyne)/fumed silica nanocomposite membranes, Chem. Mat., 15 (2002) 109-123.

[14] S. Japip, H. Wang, Y. Xiao, T. Shung Chung, Highly permeable zeolitic imidazolate framework (ZIF)-71 nano-particles enhanced polyimide membranes for gas separation, J. Membr. Sci., 467 (2014) 162-174. 
[15] T. Yang, T.-S. Chung, High performance ZIF-8/PBI nano-composite membranes for high temperature hydrogen separation consisting of carbon monoxide and water vapor, Int. J. Hydrogen Energy, 38 (2013) 229-239.

[16] L. Ge, W. Zhou, V. Rudolph, Z. Zhu, Mixed matrix membranes incorporated with sizereduced Cu-BTC for improved gas separation, J. Mat. Chem. A, 1 (2013) 6350-6358.

[17] S. Shahid, K. Nijmeijer, High pressure gas separation performance of mixed-matrix polymer membranes containing mesoporous Fe(BTC), J. Membr. Sci., 459 (2014) 33-44.

[18] A.L. Khan, S.P. Sree, J.A. Martens, M.T. Raza, I.F.J. Vankelecom, Mixed matrix membranes comprising of matrimid and mesoporous COK-12: Preparation and gas separation properties, J. Membr. Sci., 495 (2015) 471-478.

[19] R.T. Adams, J.S. Lee, T.-H. Bae, J.K. Ward, J.R. Johnson, C.W. Jones, S. Nair, W.J. Koros, $\mathrm{CO} 2-\mathrm{CH} 4$ permeation in high zeolite 4A loading mixed matrix membranes, J. Membr. Sci., 367 (2011) 197-203.

[20] M. Askari, T.-S. Chung, Natural gas purification and olefin/paraffin separation using thermal cross-linkable co-polyimide/ZIF-8 mixed matrix membranes, J. Membr. Sci., 444 (2013) 173-183.

[21] X. Ma, R. Swaidan, B. Teng, H. Tan, O. Salinas, E. Litwiller, Y. Han, I. Pinnau, Carbon molecular sieve gas separation membranes based on an intrinsically microporous polyimide precursor, Carbon, 62 (2013) 88-96.

[22] Y.H. Sim, H. Wang, F.Y. Li, M.L. Chua, T.-S. Chung, M. Toriida, S. Tamai, High performance carbon molecular sieve membranes derived from hyperbranched polyimide precursors for improved gas separation applications, Carbon, 53 (2013) 101-111.

[23] C.W. Jones, W.J. Koros, Carbon molecular sieve gas separation membranes-I. Preparation and characterization based on polyimide precursors, Carbon, 32 (1994) 1419-1425.

[24] C.J. Anderson, S.J. Pas, G. Arora, S.E. Kentish, A.J. Hill, S.I. Sandler, G.W. Stevens, Effect of pyrolysis temperature and operating temperature on the performance of nanoporous carbon membranes, J. Membr. Sci., 322 (2008) 19-27.

[25] C.J. Anderson, W. Tao, J. Jiang, S.I. Sandler, G.W. Stevens, S.E. Kentish, An experimental evaluation and molecular simulation of high temperature gas adsorption on nanoporous carbon, Carbon, 49 (2011) 117-125.

[26] M.B. Rao, S. Sircar, Nanoporous carbon membrane for gas separation, Gas. Sep. Purif., 7 (1993) 279-284.

[27] R.M. Barrer, E. Strachan, Sorption and Surface Diffusion in Microporous Carbon Cylinders, Proceedings of the Royal Society of London. Series A. Mathematical and Physical 
Sciences, 231 (1955) 52-74.

[28] C.J. Anderson, W. Tao, C.A. Scholes, G.W. Stevens, S.E. Kentish, The performance of carbon membranes in the presence of condensable and non-condensable impurities, J. Membr. Sci., 378 (2011) 117-127.

[29] S. Kanehashi, G.Q. Chen, C.A. Scholes, B. Ozcelik, C. Hua, L. Ciddor, P.D. Southon, D.M. D’Alessandro, S.E. Kentish, Enhancing gas permeability in mixed matrix membranes through tuning the nanoparticle properties, J. Membr. Sci., 482 (2015) 49-55.

[30] S. Kanehashi, G.Q. Chen, L. Ciddor, A. Chaffee, S.E. Kentish, The impact of water vapor on CO2 separation performance of mixed matrix membranes, J. Membr. Sci., 492 (2015) 471477.

[31] M. Valero, B. Zornoza, C. Téllez, J. Coronas, Mixed matrix membranes for gas separation by combination of silica MCM-41 and MOF NH2-MIL-53(Al) in glassy polymers, Microporous Mesoporous Mater., 192 (2014) 23-28.

[32] G.Q. Chen, C.A. Scholes, C.M. Doherty, A.J. Hill, G.G. Qiao, S.E. Kentish, The thickness dependence of Matrimid films in water vapor permeation, Chem. Eng. J., 209 (2012) 301-312. [33] S. Matteucci, V.A. Kusuma, S.D. Kelman, B.D. Freeman, Gas transport properties of MgO filled poly(1-trimethylsilyl-1-propyne) nanocomposites, Polymer, 49 (2008) 1659-1675.

[34] S. Kanehashi, M. Kishida, T. Kidesaki, R. Shindo, S. Sato, T. Miyakoshi, K. Nagai, CO2 separation properties of a glassy aromatic polyimide composite membranes containing highcontent 1-butyl-3-methylimidazolium bis(trifluoromethylsulfonyl)imide ionic liquid, J. Membr. Sci., 430 (2013) 211-222.

[35] C.A. Scholes, S. Kanehashi, G.W. Stevens, S.E. Kentish, Water permeability and competitive permeation with $\mathrm{CO} 2$ and $\mathrm{CH} 4$ in perfluorinated polymeric membranes, Sep. Purif. Technol., 147 (2015) 203-209.

[36] S. Kanehashi, K. Nagai, Analysis of dual-mode model parameters for gas sorption in glassy polymers, J. Membr. Sci., 253 (2005) 117-138.

[37] X. Duthie, S. Kentish, C. Powell, K. Nagai, G. Qiao, G. Stevens, Operating temperature effects on the plasticization of polyimide gas separation membranes, J. Membr. Sci., 294 (2007) 40-49.

[38] A. Halim, Q. Fu, Q. Yong, P.A. Gurr, S.E. Kentish, G.G. Qiao, Soft polymeric nanoparticle additives for next generation gas separation membranes, J. Mat. Chem. A, 2 (2014) 4999-5009. [39] G.Q. Chen, C.A. Scholes, G.G. Qiao, S.E. Kentish, Water vapor permeation in polyimide membranes, J. Membr. Sci., 379 (2011) 479-487.

[40] T.-S. Chung, S.S. Chan, R. Wang, Z. Lu, C. He, Characterization of permeability and 
sorption in Matrimid/C60 mixed matrix membranes, J. Membr. Sci., 211 (2003) 91-99.

[41] S. Matteucci, V.A. Kusuma, D. Sanders, S. Swinnea, B.D. Freeman, Gas transport in TiO2 nanoparticle-filled poly(1-trimethylsilyl-1-propyne), J. Membr. Sci., 307 (2008) 196-217.

[42] J.A. Thompson, K.W. Chapman, W.J. Koros, C.W. Jones, S. Nair, Sonication-induced Ostwald ripening of ZIF-8 nanoparticles and formation of ZIF-8/polymer composite membranes, Micropor. Mesopor. Mater., 158 (2012) 292-299.

[43] Q. Song, S.K. Nataraj, M.V. Roussenova, J.C. Tan, D.J. Hughes, W. Li, P. Bourgoin, M.A. Alam, A.K. Cheetham, S.A. Al-Muhtaseb, E. Sivaniah, Zeolitic imidazolate framework (ZIF8) based polymer nanocomposite membranes for gas separation, Energy Environ. Sci., 5 (2012) 8359-8369.

[44] H.-Y. Zhao, Y.-M. Cao, X.-L. Ding, M.-Q. Zhou, J.-H. Liu, Q. Yuan, Poly(ethylene oxide) induced cross-linking modification of Matrimid membranes for selective separation of $\mathrm{CO} 2, \mathrm{~J}$. Membr. Sci., 320 (2008) 179-184.

[45] T.T. Moore, W.J. Koros, Non-ideal effects in organic-inorganic materials for gas separation membranes, Journal of Molecular Structure, 739 (2005) 87-98.

[46] P.S. Tin, T.S. Chung, Y. Liu, R. Wang, S.L. Liu, K.P. Pramoda, Effects of cross-linking modification on gas separation performance of Matrimid membranes, J. Membr. Sci., 225 (2003) 77-90.

[47] B.E. Poling, J.M. Prausnitz, J.P. O'Connell, The Properties of Gases and Liquids, 5th Ed ed., Fifth Ed., McGraw-Hill, New York, 2000.

[48] S. Kanehashi, Development of hybrid membranes for carbon capture, Kobunshi Ronbunshu, 73 (2016) 475-490.

[49] O.G. Nik, X.Y. Chen, S. Kaliaguine, Functionalized metal organic framework-polyimide mixed matrix membranes for CO2/CH4 separation, J. Membr. Sci., $413-414$ (2012) 48-61.

[50] C. Duan, X. Jie, D. Liu, Y. Cao, Q. Yuan, Post-treatment effect on gas separation property of mixed matrix membranes containing metal organic frameworks, J. Membr. Sci., 466 (2014) 92-102.

[51] S. Kanehashi, T. Nakagawa, K. Nagai, X. Duthie, S. Kentish, G. Stevens, Effects of carbon dioxide-induced plasticization on the gas transport properties of glassy polyimide membranes, J. Membr. Sci., 298 (2007) 147-155.

[52] X. Duthie, S. Kentish, S.J. Pas, A.J. Hill, C. Powell, K. Nagai, G. Stevens, G. Qiao, Thermal treatment of dense polyimide membranes, J. Polym. Sci. Part B: Polym. Phys., 46 (2008) 1879-1890.

[53] C.A. Scholes, G.W. Stevens, S.E. Kentish, Membrane gas separation applications in 
natural gas processing, Fuel, 96 (2012) 15-28.

[54] T.T. Moore, W.J. Koros, Gas sorption in polymers, molecular sieves, and mixed matrix membranes, J. Appl. Polym. Sci., 104 (2007) 4053-4059.

[55] C.A. Scholes, W.X. Tao, G.W. Stevens, S.E. Kentish, Sorption of methane, nitrogen, carbon dioxide, and water in Matrimid 5218, J. Appl. Polym. Sci., 117 (2010) 2284-2289.

[56] Z. Peng, Z. Guo, W. Chu, M. Wei, Facile synthesis of high-surface-area activated carbon from coal for supercapacitors and high CO2 sorption, RSC Adv., 6 (2016) 42019-42028.

[57] S.S. Hosseini, M.M. Teoh, T.S. Chung, Hydrogen separation and purification in membranes of miscible polymer blends with interpenetration networks, Polymer, 49 (2008) 1594-1603.

[58] A.L. Khan, X. Li, I.F.J. Vankelecom, SPEEK/Matrimid blend membranes for CO2 separation, J. Membr. Sci., 380 (2011) 55-62.

[59] S. Shishatskiy, C. Nistor, M. Popa, S.P. Nunes, K.V. Peinemann, Polyimide asymmetric membranes for hydrogen separation: influence of formation conditions on gas transport properties, Adv. Eng. Mater., 8 (2006) 390-397. 


\section{Figure Captions}

$\begin{array}{ll}\text { Figure } 1 & \text { (a) The effect of filler loading on the membrane density where the solid lines }\end{array}$ represent the best fit to the experimental data while the dashed lines represent Equation (2). (b) the effect of the void volume generated between the nanoparticles and the polymer on the fractional free volume $(F F V)$ where Equation (5) gives the results without a void fraction and Equation (6) includes this void volume.

Figure 2 Effect of filler loading on the polymer glass transition temperature.

Figure 3 WAXD profiles of Matrimid, carbon-based mixed matrix membranes, and pure carbon nanoparticles.

Figure 4 Effect of filler loading on (a) dry pure gas permeability and (b) pure gas selectivity of MMMs using carbon determined by CVVP method.

Figure 5 Dry pure and mixed $\mathrm{CO}_{2} / \mathrm{CH}_{4}$ permeability in Matrimid and $20 \mathrm{wt} \%$ mixed matrix membrane as a function of total feed pressure at $35^{\circ} \mathrm{C}$ determined by the CPVV method. Solid and dashed lines represent pure and mixed gas data, respectively.

Figure 6 The time dependence of the increase in $\mathrm{CO}_{2}$ permeability at 10 bar feed pressure and $35^{\circ} \mathrm{C}$ for pure $\mathrm{CO}_{2}$ (normalized to the permeability after one hour) in pure Matrimid and the $20 \mathrm{wt} \%$ mixed matrix membrane. Results determined by the CPVV method.

Figure $7 \quad \mathrm{CO}_{2}$ sorption isotherms for Matrimid, pure carbon, and a $20 \mathrm{wt} \%$ mixed matrix membrane. The solid lines represent the best fit to the dual mode sorption model (Equation (11)).

Figure 8 Average diffusion coefficients in Matrimid and $20 \mathrm{wt} \%$ mixed matrix membrane as a function of feed pressure at $35^{\circ} \mathrm{C}$. 
Figure 9 Water vapor permeability Matrimid and $20 \mathrm{wt} \%$ mixed matrix membrane as a function of feed water activity at $35^{\circ} \mathrm{C}$ and 7.5 bar in a mixture of $10 \% \mathrm{CO}_{2}$ in $\mathrm{CH}_{4}$.

Figure 10 The permeability of a $20 \mathrm{wt} \%$ mixed matrix membrane in a gas mixture of $10 \% \mathrm{CO}_{2}$ in $\mathrm{N}_{2}$ at 7.5 bar and $35^{\circ} \mathrm{C}$ as a function of time under both dry conditions and at a humidity of $\alpha>0.9$.

\section{Table Captions}

Table $1 \quad$ Physical properties of the carbon nanoparticles.

Table 2 Dual mode sorption parameters of the carbon nanoparticles, the MMM (20wt\%) and pure Matrimid. 

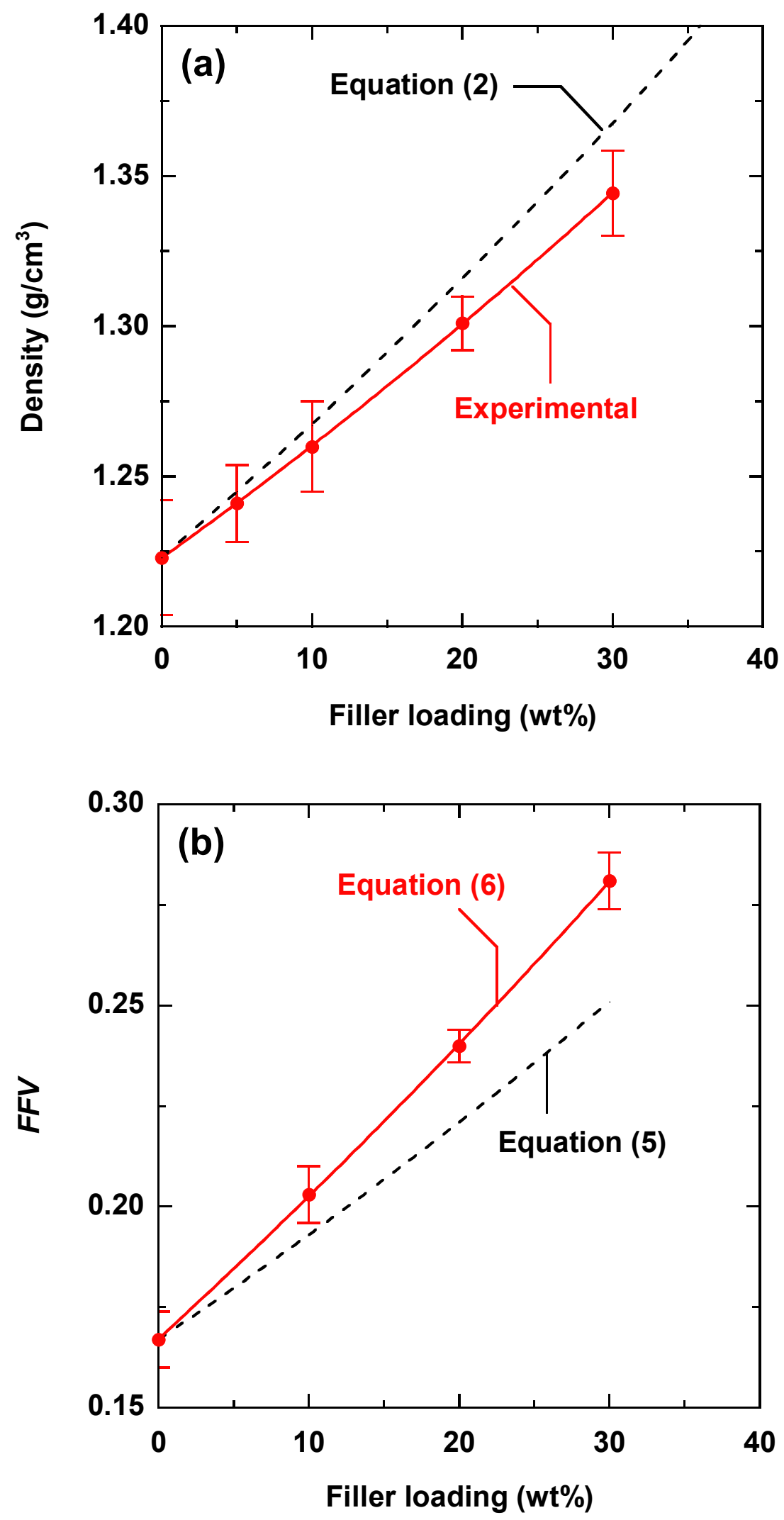

Figure 1 (Kanehashi et al.) 


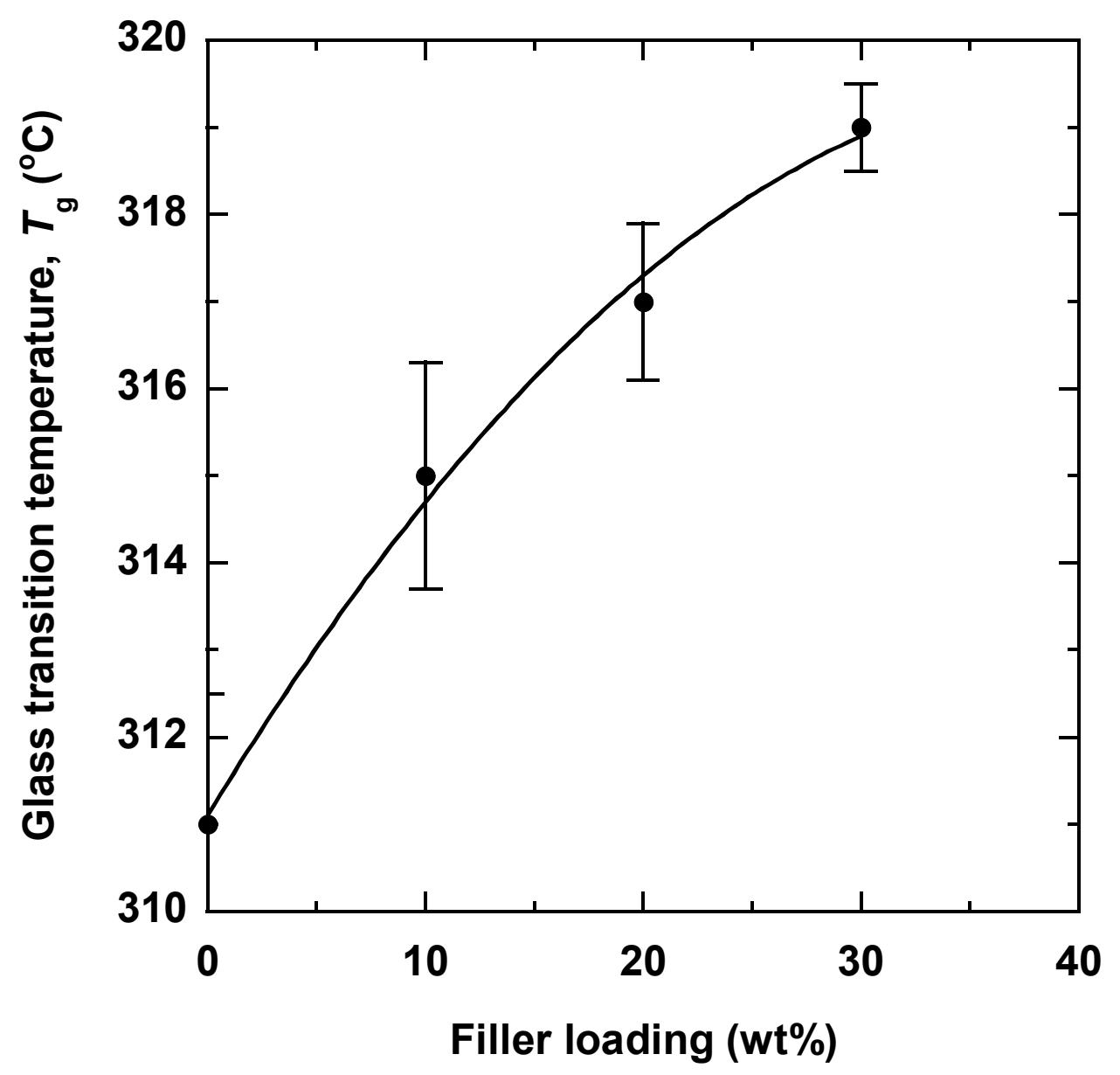

Figure 2 (Kanehashi et al.) 


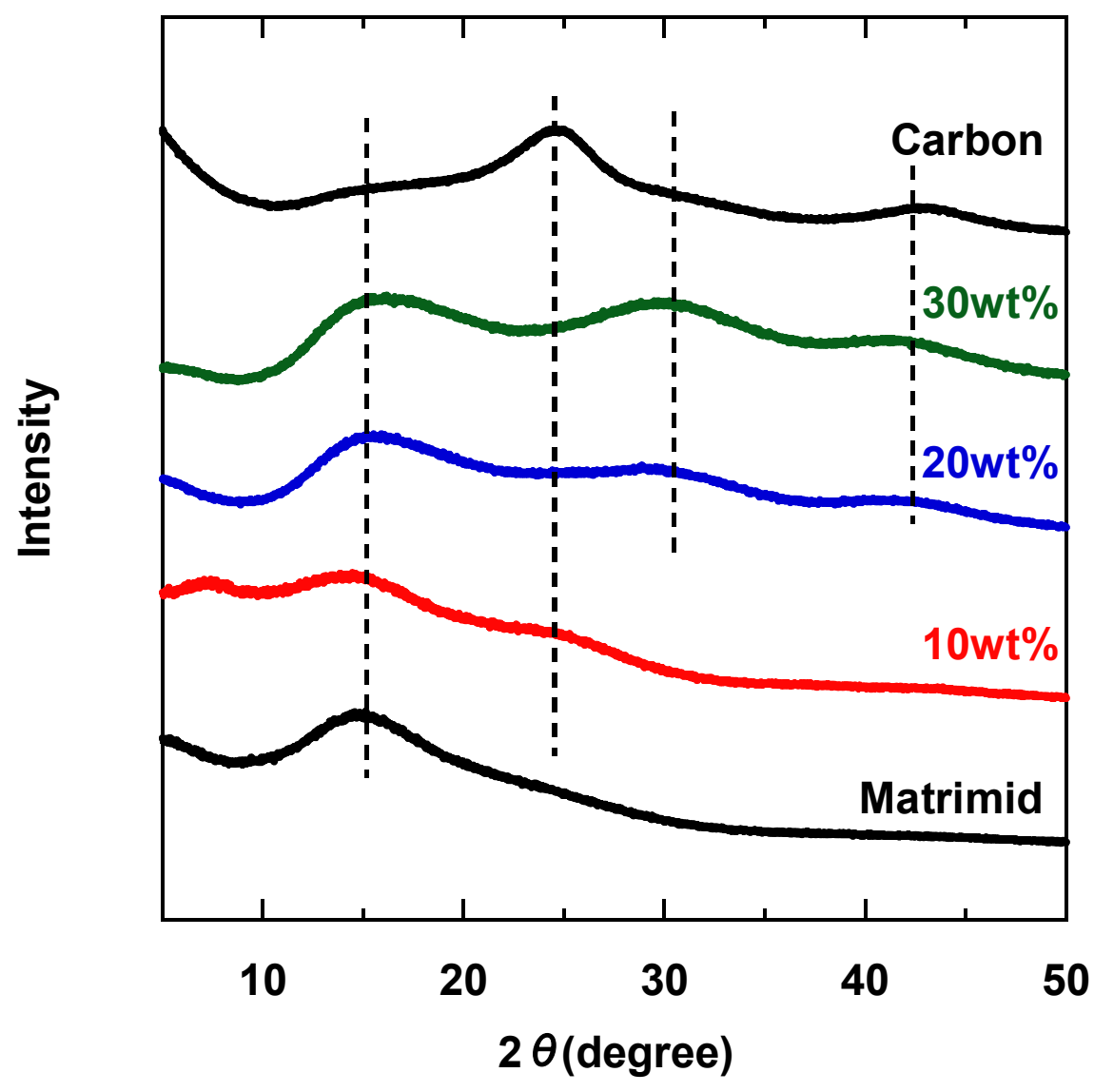

Figure 3 (Kanehashi et al.) 

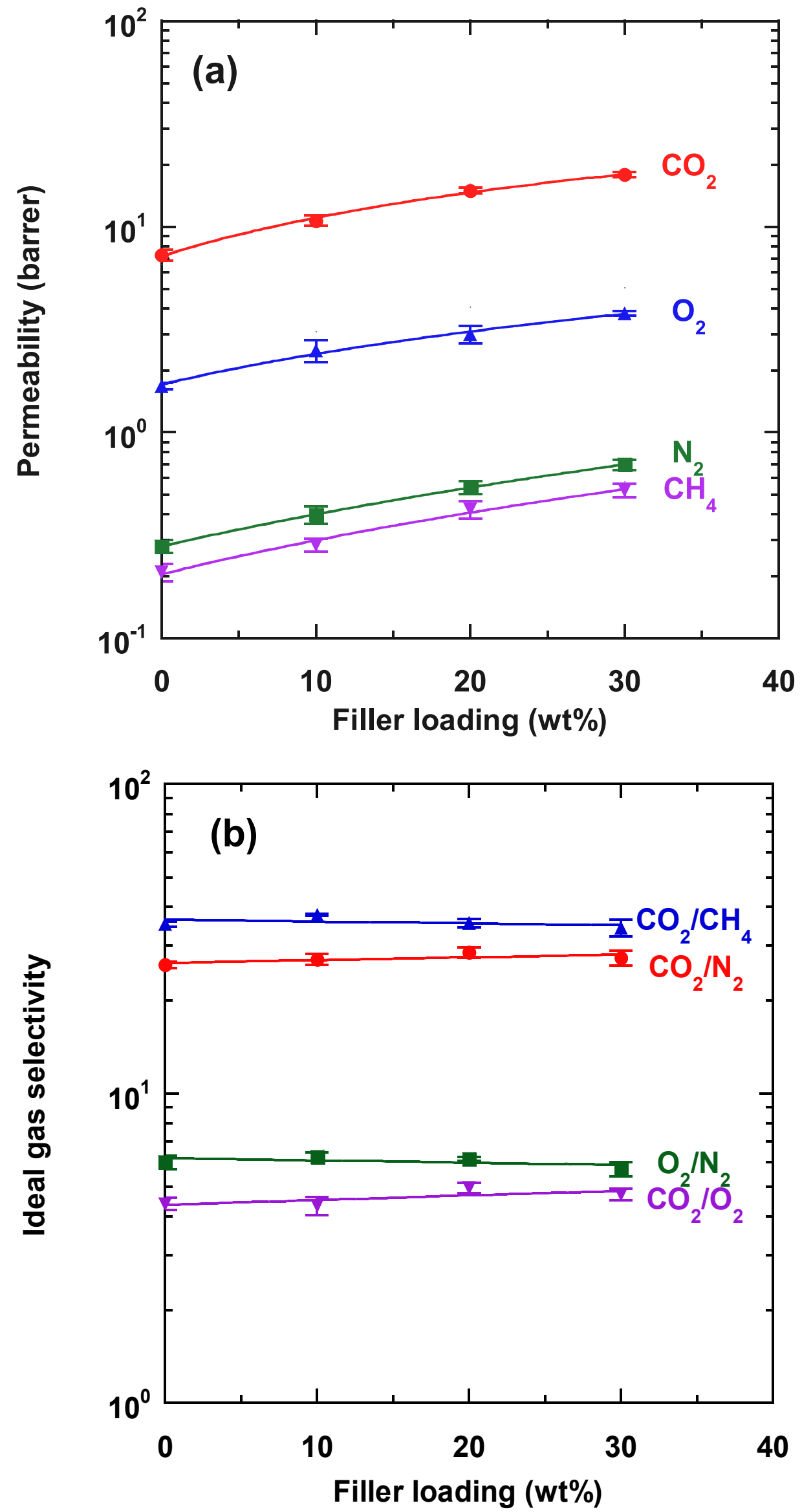

Figure 4 (Kanehashi et al.) 

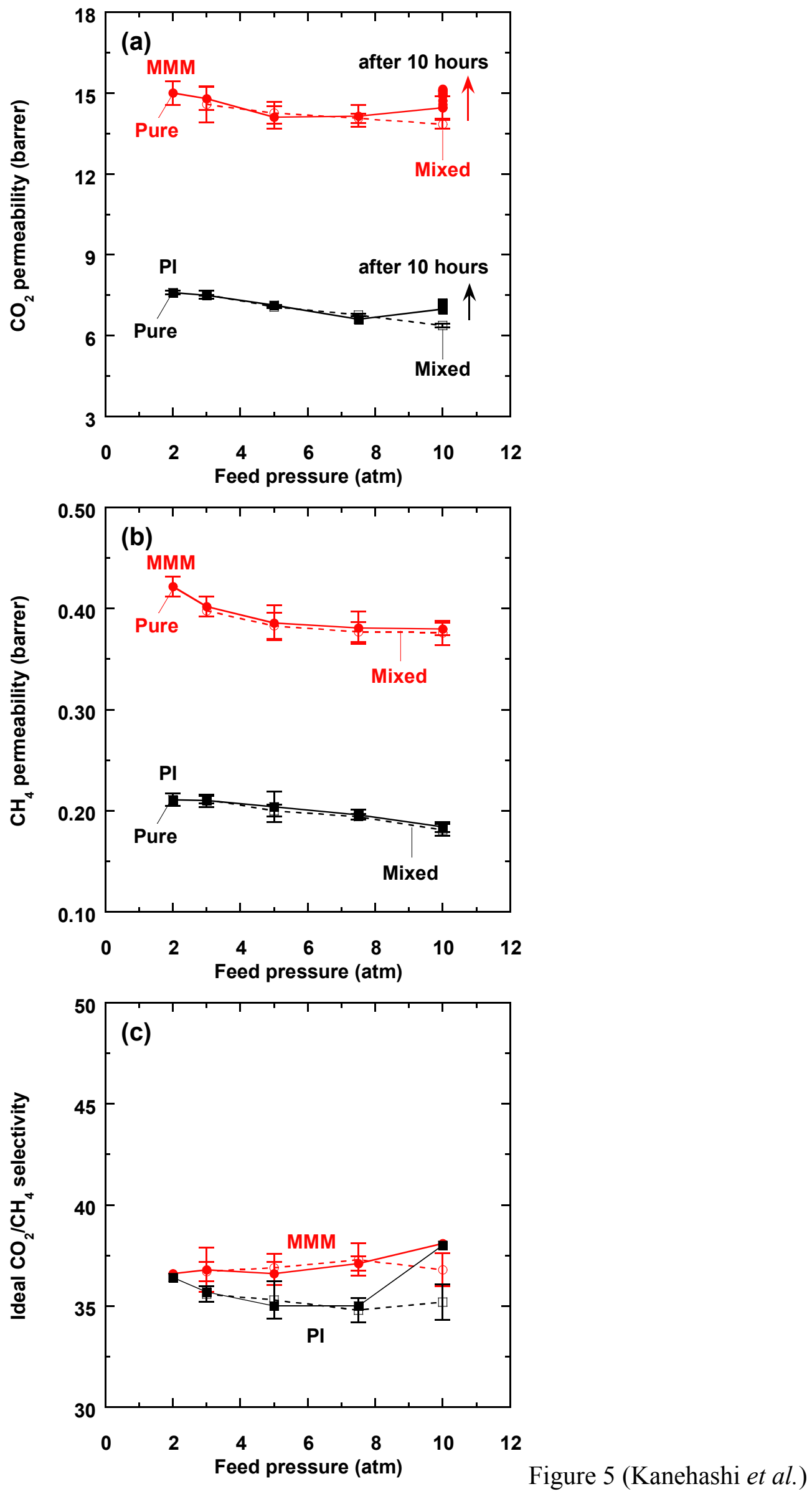


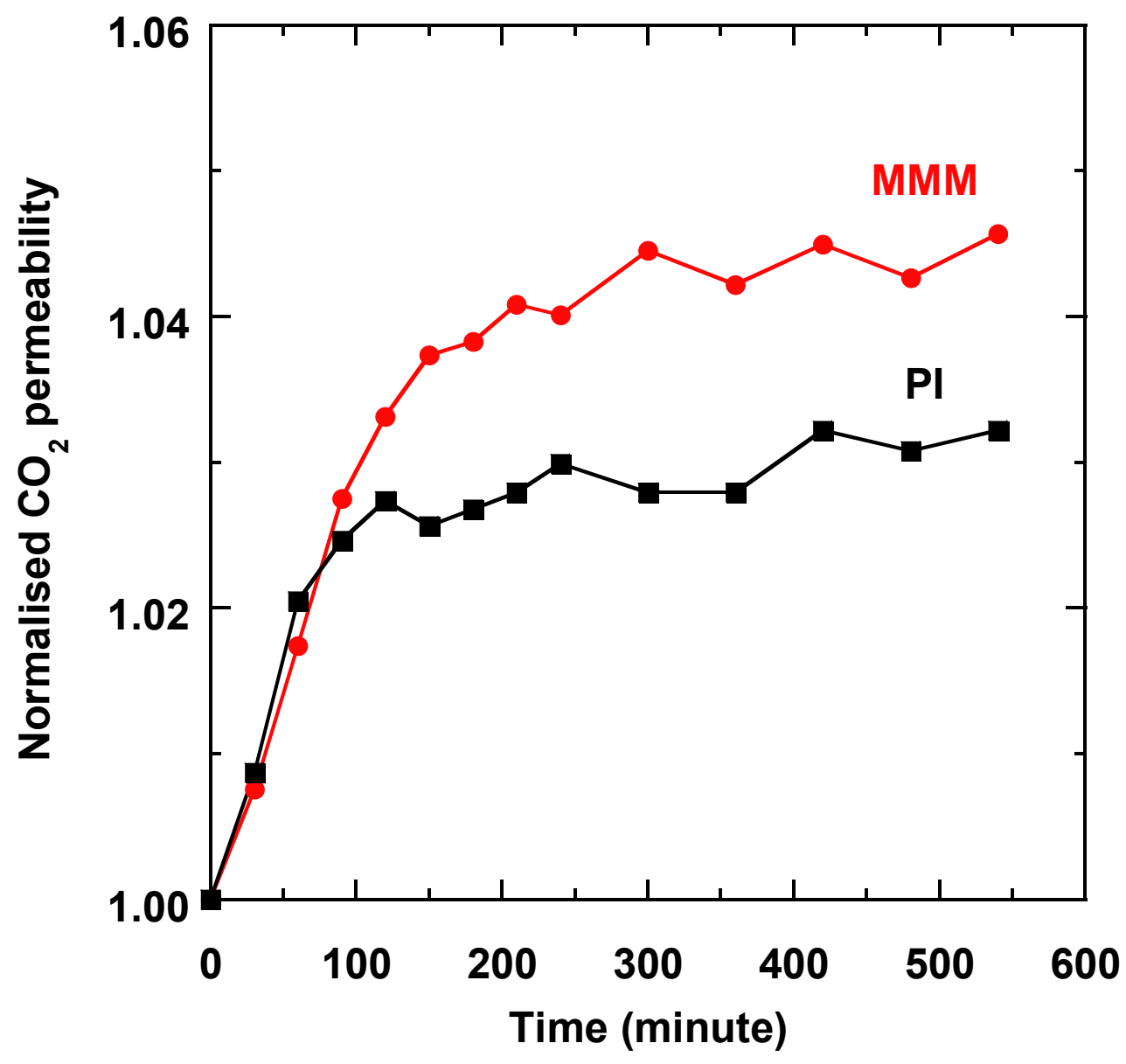

Figure 6 (Kanehashi et al.) 


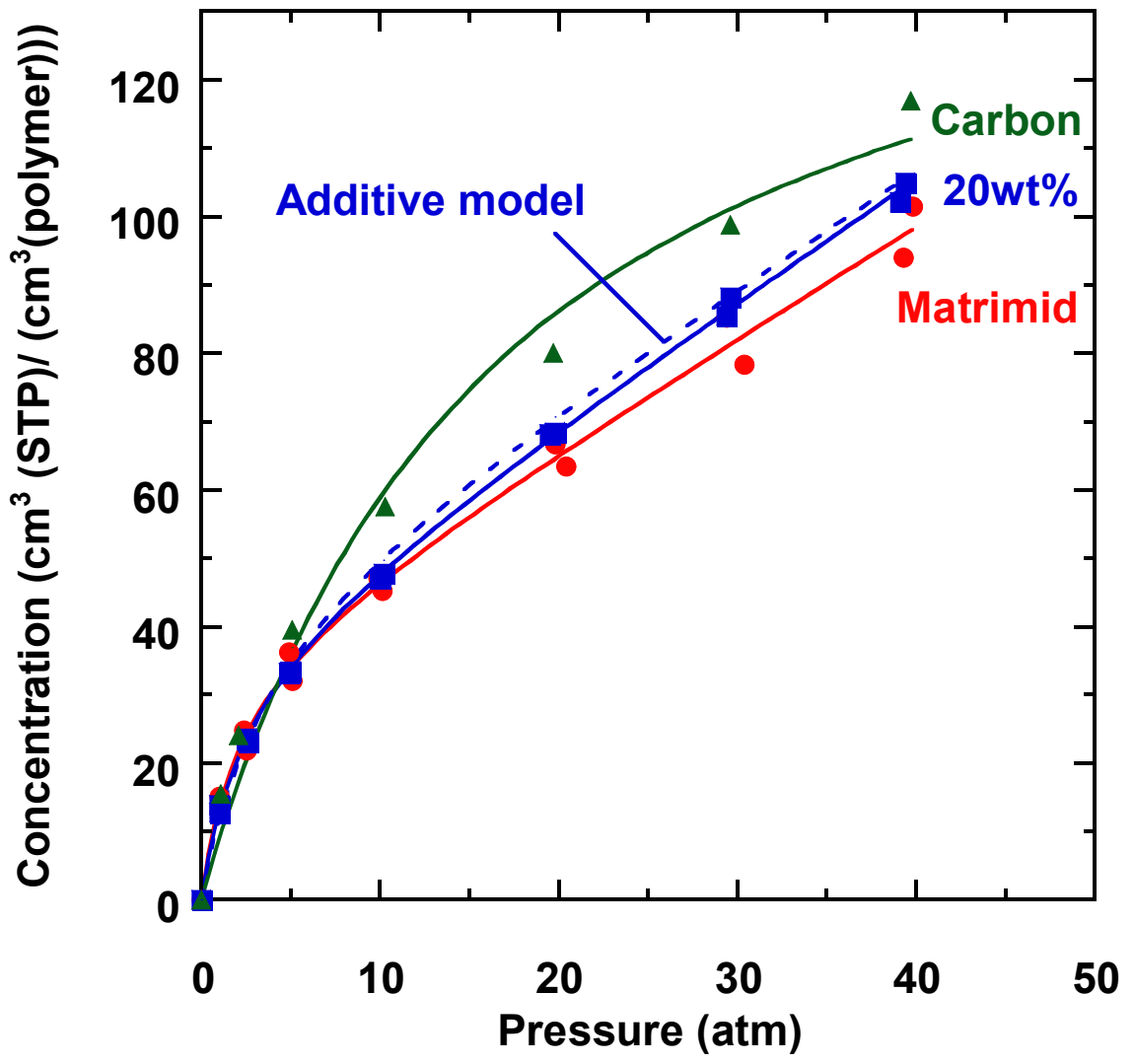

Figure 7 (Kanehashi et al.) 


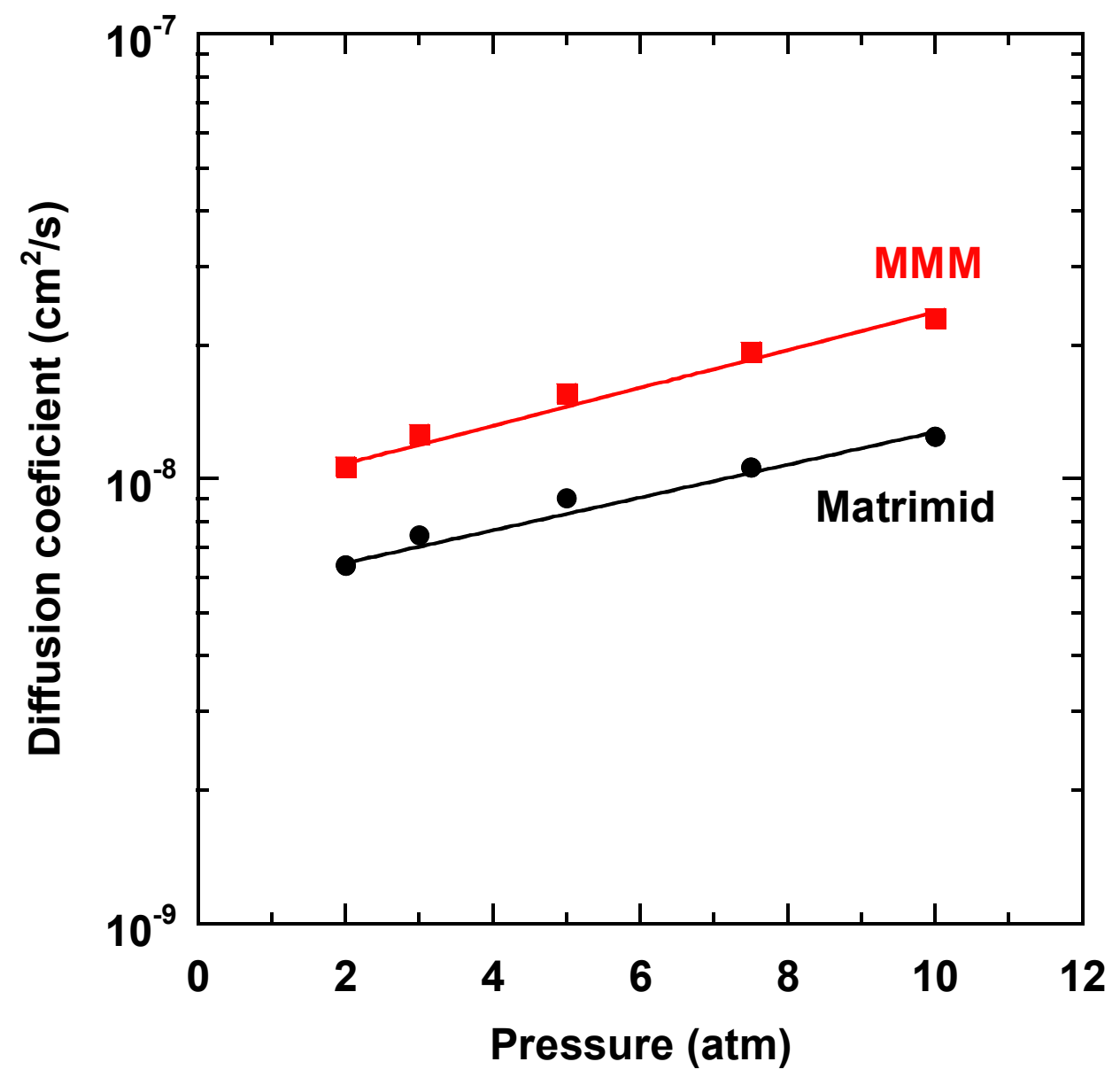

Figure 8 (Kanehashi et al.) 


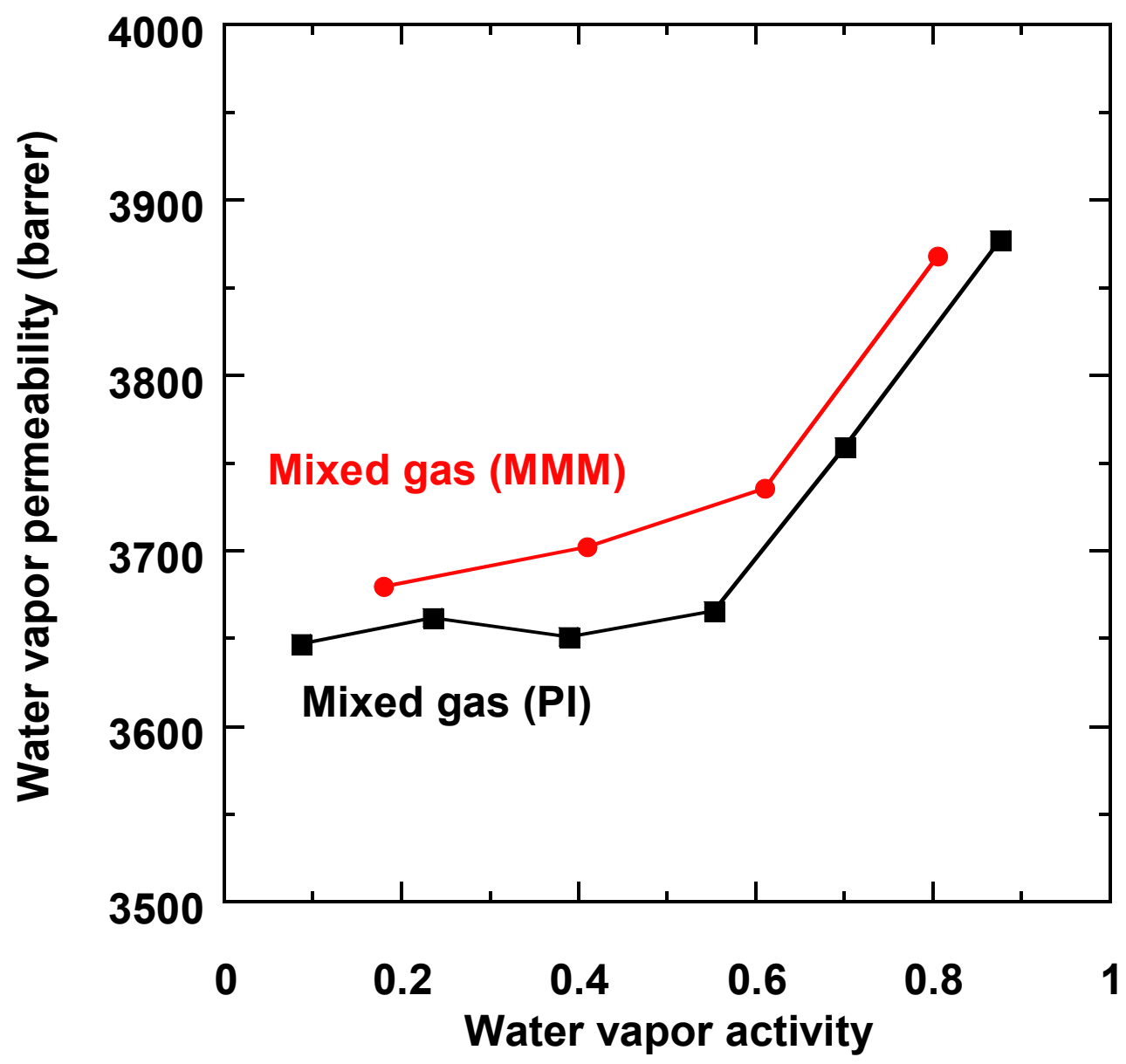

Figure 9 (Kanehashi et al.) 

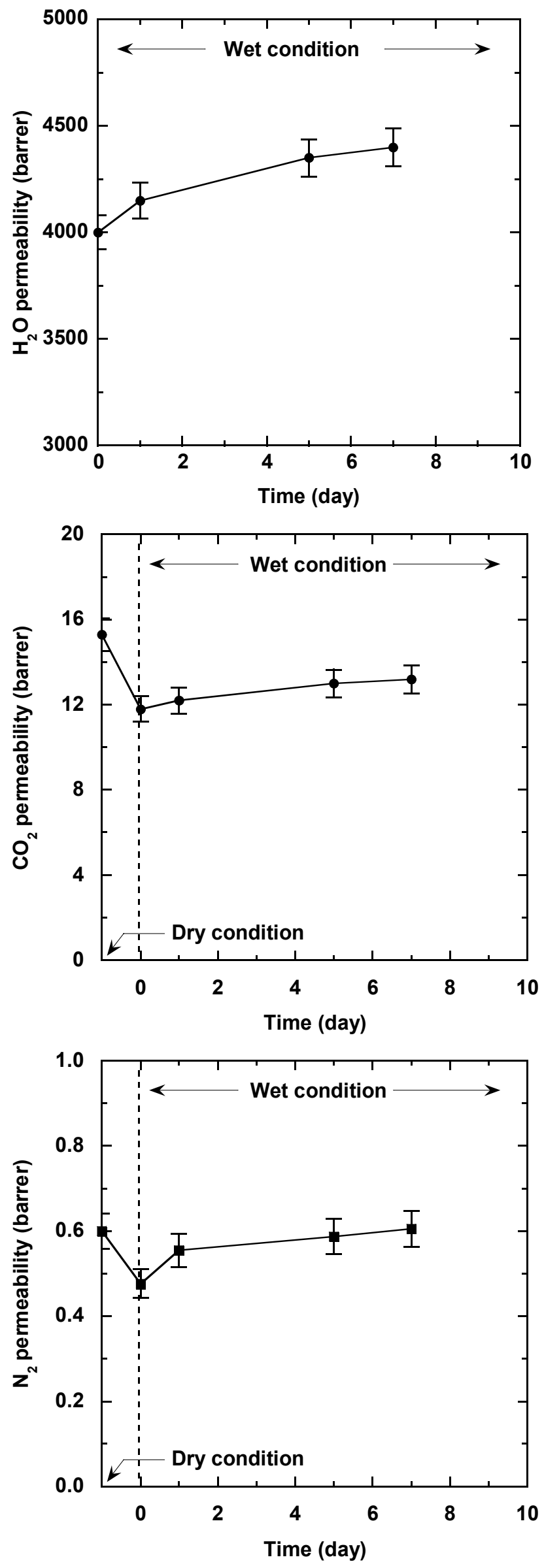

Figure 10 (Kanehashi et al.) 
Table 1 Physical properties of the carbon nanoparticles

\begin{tabular}{cc}
\hline Property & Carbon \\
\hline Average particle size $(\mathrm{nm})^{(\mathrm{a})}$ & 180 \\
Surface area $\left(\mathrm{m}^{2} / \mathrm{g}\right)^{(\mathrm{b})}$ & 252 \\
Pore volume $\left(\mathrm{cm}^{3} / \mathrm{g}\right)^{(\mathrm{b})}$ & 0.286 \\
Average pore diameter $(\AA)^{(\mathrm{c})}$ & 64 \\
Absolute density $\left(\mathrm{g} / \mathrm{cm}^{3}\right)^{(\mathrm{c})}$ & 1.887 \\
Free volume $^{(\mathrm{d})}$ & 0.540 \\
\hline
\end{tabular}
(a) From dynamic light scattering
(b) Determined from $\mathrm{N}_{2}$ BET sorption analysis
(c) Manufacturer information
(d) Calculated in this work from the particle pore volume and density 
Table 2 Dual mode sorption parameters of the carbon nanoparticles, the MMM (20wt $\%)$ and pure Matrimid

\begin{tabular}{|c|c|c|c|c|}
\hline Sample & $\begin{array}{c}k_{D} \\
\mathrm{~cm}^{3} \\
(\mathrm{STP}) / \mathrm{cm}^{3}\end{array}$ & $\begin{array}{r}C_{H}^{\prime} \\
\mathrm{cm}^{3}(\mathrm{STP}) / \mathrm{cm}^{3}\end{array}$ & $\mathrm{mmol} / \mathrm{g}$ & $\begin{array}{c}b \\
\mathrm{~atm}^{-1}\end{array}$ \\
\hline Carbon & - & $158 \pm 15$ & $3.7 \pm 0.3$ & $0.060 \pm 0.013$ \\
\hline Activated Carbon [56] & - & - & $6-20$ & $0.057-0.12$ \\
\hline MMM (20wt $\%)$ & $1.76 \pm 0.04$ & $37.4 \pm 1.6$ & - & $0.41 \pm 0.04$ \\
\hline Matrimid & $1.59 \pm 0.12$ & $36.0 \pm 4.0$ & - & $0.49 \pm 0.15$ \\
\hline (a) Matrimid [40] & 1.42 & 35.0 & - & 0.702 \\
\hline (b) Matrimid [54] & 1.44 & 25.5 & - & 0.367 \\
\hline
\end{tabular}


- Mixed matrix membranes(MMM) prepared from carbon nanoparticles in Matrimid

- $\mathrm{CO}_{2}$ solubility isotherms for MMM predicted by simple addition of component isotherms.

- $\mathrm{CO}_{2}$ diffusivity increased uniformly as a result of additional free volume.

- Nanoparticles were unable to prevent plasticisation by water or $\mathrm{CO}_{2}$

- The use of sub-micron nanoparticles may relate to the lack of plasticisation resistance. 